\title{
Article \\ Poly Lactic-co-Glycolic Acid-Coated Toluidine Blue Nanoparticles for the Antibacterial Therapy of Wounds
}

\author{
Xiaomu Xu ${ }^{\dagger}$, Bo Liu ${ }^{\dagger}$, Haiyan Wu, Yichi Zhang, Xinyuan Tian, Jijing Tian * and Tianlong Liu * \\ Laboratory of Veterinary Pathology and Nanopathology, College of Veterinary Medicine, \\ China Agricultural University, No. 2 West Road Yuanmingyuan, Beijing 100193, China; \\ xuxiaomu92@126.com (X.X.); liubo19900409@163.com (B.L.); wuhaiyan_helen@sina.com (H.W.); \\ zhangyichi142857@163.com (Y.Z.); tianxy@cau.edu.cn (X.T.) \\ * Correspondence: jjtian@cau.edu.cn (J.T.); liutianlong@cau.edu.cn (T.L.); Tel.: +86-010-62733398 (T.L.) \\ + These authors contributed equally to this work.
}

Citation: Xu, X.; Liu, B.; Wu, H.; Zhang, Y.; Tian, X.; Tian, J.; Liu, T. Poly Lactic-co-Glycolic Acid-Coated Toluidine Blue Nanoparticles for the Antibacterial Therapy of Wounds. Nanomaterials 2021, 11, 3394.

https://doi.org/10.3390/ nano11123394

Academic Editor: Rosalia Bertorelli

Received: 21 October 2021

Accepted: 9 December 2021

Published: 14 December 2021

Publisher's Note: MDPI stays neutral with regard to jurisdictional claims in published maps and institutional affiliations.

Copyright: (C) 2021 by the authors. Licensee MDPI, Basel, Switzerland. This article is an open access article distributed under the terms and conditions of the Creative Commons Attribution (CC BY) license (https:// creativecommons.org/licenses/by/ $4.0 /)$.
Abstract: Bacterial infections in wounded skin are associated with high mortality. The emergence of drug-resistant bacteria in wounded skin has been a challenge. Toluidine blue (TB) is a safe and inexpensive photosensitizer that can be activated and used in near-infrared photodynamic therapy to effectively kill methicillin-resistant Staphylococcus aureus (MRSA). However, its aggregation-induced quenching effect largely affects its clinical applications. In this study, TB nanoparticles (NPs) were synthesized using an ultrasound-assisted coating method. Their physicochemical and biological properties were studied and evaluated by scanning electron microscopy and Fourier-transform infrared spectroscopy. The TBNPs had a broad-spectrum antibacterial activity against Gram-positive bacteria (MRSA) and Gram-negative bacteria (E. coli). In addition, MTT, hemolysis, and acute toxicity tests confirmed that TBNPs had good biocompatibility. The TBNPs exhibited a high photodynamic performance under laser irradiation and efficiently killed E. coli and MRSA through generated reactive oxygen species, which destroyed the cell wall structure. The potential application of TBNPs in vivo was studied using an MRSA-infected wound model. The TBNPs could promote wound healing within 7 days, mainly by reducing the inflammation and promoting collagen deposition and granulation tissue formation. In conclusion, the TBNPs offer a promising strategy for clinical applications against multiple-drug resistance.

Keywords: photodynamic therapy; toluidine blue nanoparticles; wound healing; antibacterial

\section{Introduction}

The skin is the largest organ of the body. Its primary function is to protect against pathogenic microbial infections, chemical agents, and mechanical damage [1,2]. When skin is damaged by external agents or microbes, its function as a barrier against organisms is affected, in addition to its temperature regulation and immune regulation abilities [3]. Once wounded, bleeding, inflammation, and bacterial infection may occur [4]. It is, therefore, challenging to cure wounds; in particular, the emergence of drug-resistant microorganisms, which further complicates the situation, makes it more arduous [5]. Drug-resistant microorganisms, such as methicillin-resistant Staphylococcus aureus (MRSA), have become a major health care concern worldwide [6-8]. Approximately half of all skin infections arise due to MRSA. Therefore, a multi-functional antimicrobial agent is needed to overcome this problem.

Recently, photodynamic therapy (PDT), a novel antimicrobial treatment, has attracted increasing attention in clinical applications and animal disease models [9-11] because of its unique antibacterial mechanism, which is less likely to cause drug resistance in bacteria [12,13]. A hundred years ago, PDT was used to treat various skin diseases, such as skin cancer and acne [14-16]. PDT has become an alternative tool to replace antibacterial drugs. Light, oxygen, and a photosensitizer are the important factors in PDT. 
It is generally believed that the bactericidal mechanism of PDT involves the production of reactive oxygen intermediates (such as singlet oxygen and hydrogen peroxide) under light exposure, eventually leading to cell death by apoptosis or necrosis [17,18].

In this study, a nanospray was synthesized, and PDT was used to treat wounds infected by bacteria. Toluidine blue (TB) is a conventional photosensitizer. TB-mediated PDT has good antibacterial and healing properties against bacterial keratitis and skin infections [19]. However, the clinical application of TB is limited mainly because of the aggregation-induced quenching (ACQ) effect. In addition, it is challenging to maintain the target site for a long time $[20,21]$. Therefore, TB was modified with poly lactic-coglycolic acid (PLGA) to improve its antibacterial effect. PLGA is a macromolecular organic compound with good biocompatibility and biodegradability [22]. PLGA is widely used as a biomedical material for various applications, including drug carriers, medical/surgical materials, and tissue engineering [23-25]. It has been approved by the Food and Drug Administration (FDA) as a clinical wound dressing. PLGA promotes angiogenesis and accelerates wound healing [26,27]. Multi-functional TB nanoparticles (NPs) were prepared for the treatment of MRSA infection (Scheme 1). PLGA-coated TBNPs were prepared to treat $E$. coli and MRSA infections. The conventional plate count method and minimum inhibitory concentration (MIC) test were used to evaluate the antibacterial effect of TBNPs in vitro. In addition, the therapeutic effects of TBNPs on skin infections caused by MRSA were evaluated in mice.

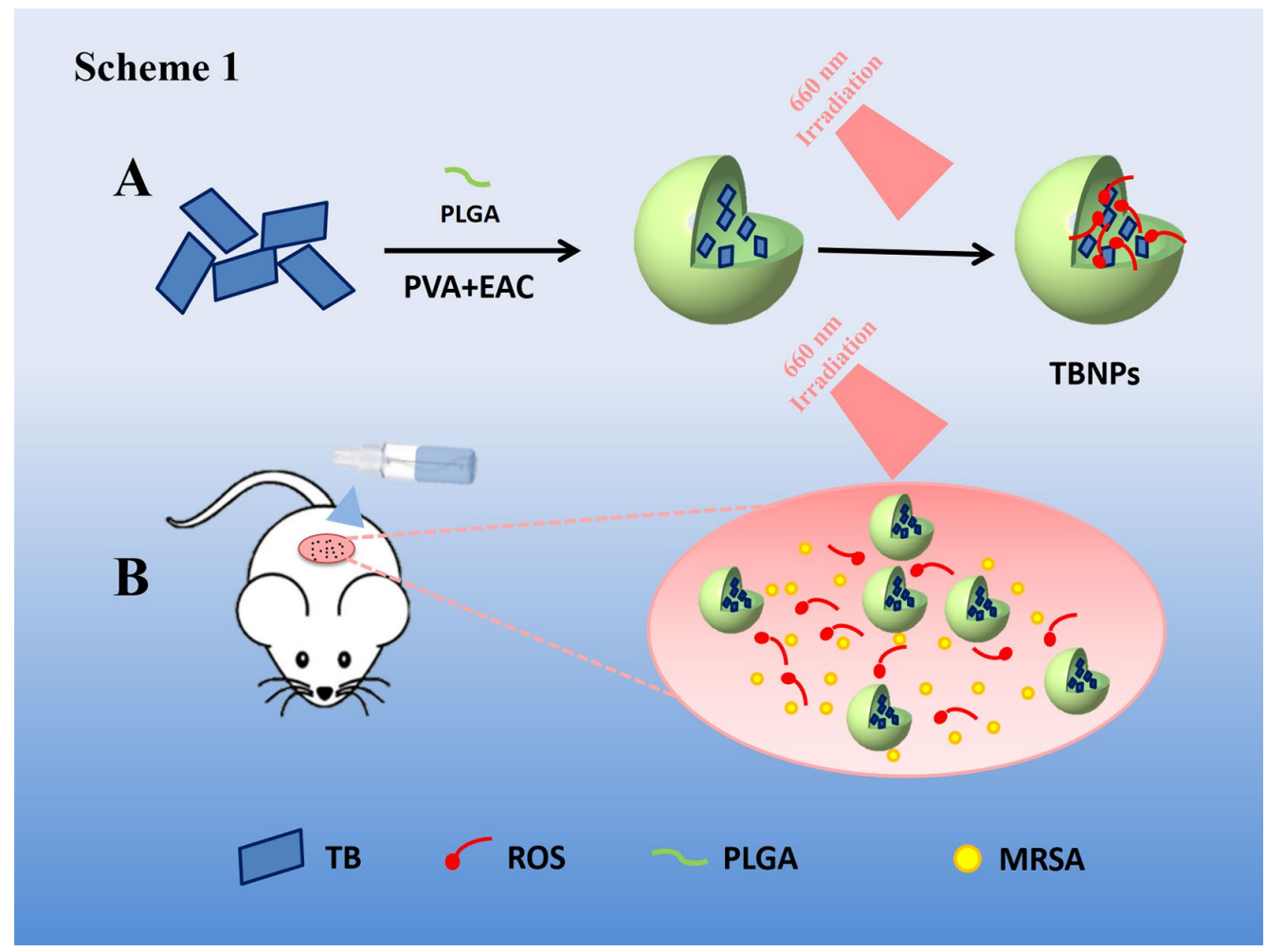

Scheme 1. Experiment diagrams. (A) Schematic of the synthetic route of TBNPs. (B) Schematic of TBNPs producing an increased number of reactive oxygen species (ROS) under $660 \mathrm{~nm}$ laser irradiation in a wound.

\section{Materials and Methods}

Preparation of TBNPs. A TB solution $(10 \mathrm{mg} / \mathrm{mL})$ with $3 \% \mathrm{NaCl}$ was used as an internal aqueous phase. PVA solutions of concentrations $1 \%$ and $0.5 \%$ were configured as external aqueous phases. PLGA (200 mg) was dissolved in $5.5 \mathrm{~mL}$ of ethyl acetate, and $0.5 \mathrm{~mL}$ of the internal aqueous phase was added into oil phase. Colostrum was formed by ultrasound in the ice bath and was poured into $10 \mathrm{~mL}$ of the $1 \%$ PVA external aqueous 
phase. The premixed milk was prepared in an ultrasonic ice bath for $10 \mathrm{~min}$ (operation for $3 \mathrm{~s}$, pause for $3 \mathrm{~s}$ ). The premixed milk was poured into $10 \mathrm{~mL}$ of the $0.5 \%$ PVA solution and stirred at 300-400 rpm at room temperature for 3-4 $\mathrm{h}$, which yielded PLGA NPs. The solution was then centrifuged at $4{ }^{\circ} \mathrm{C}$ at $10,000 \mathrm{rpm}$ for $10 \mathrm{~min}$. Distilled water was added for ultrasonic dispersion.

Characterization of TBNPs. The hydrodynamic size and potential of the NPs were measured using a Zetasizer nanoparticle size potentiometer (Zetasizer Nano ZS90; Malvern, UK). The morphology of the TBNPs was observed using scanning electron microscopy (SEM) (FEI Inspect F50, Hillsboro, OR, USA). The chemical structure of the TBNPs was analyzed at the molecular level using Fourier-transform infrared (FTIR) spectroscopy.

Minimum Inhibitory Concentration Test. MRSA (ATCC 25923) and E. coli (ATCC 25922) were used for MIC detection. A $5 \times 10^{5}$ colony-forming unit (CFU) $/ \mathrm{mL}$ bacterial suspension of $100 \mu \mathrm{L}$ was added to each well. TBNPs with different concentrations were added to each well in volumes of $100 \mu \mathrm{L}$. The light groups were illuminated at $660 \mathrm{~nm}$ for $5 \mathrm{~min}$ and incubated at $37^{\circ} \mathrm{C}$ for $18 \mathrm{~h}$. Resazurin of $0.0675 \%$ concentration was then prepared, and $10 \mu \mathrm{L}$ of it was added to each well and incubated at $37^{\circ} \mathrm{C}$ for $4 \mathrm{~h}$. Color changes were observed, and any well indicating color change from purple to pink or colorless was recorded as positive.

MTT Test. The cytotoxicity of TB and TBNPs was evaluated by an MTT viability assay. The light groups were illuminated at $660 \mathrm{~nm}$ for $5 \mathrm{~min}$. 4T1 cells were maintained in a high-glucose Dulbecco's modified Eagle's medium. After coincubating the 4T1 cells $\left(5 \times 10^{4} /\right.$ well $)$ with TBNPs for $24 \mathrm{~h}$ at a series dosage, MTT solution was added to each well. After $4 \mathrm{~h}$ of incubation at $37^{\circ} \mathrm{C}$, colorimetric measurements were performed at $495 \mathrm{~nm}$ using a scanning multi-well spectrometer.

In Vivo Biocompatibility Assay. Mice were divided into different groups (PBS, PBS + light, TB, TB + light, TBNPs, and TBNPs + light; 5 mice in each group) and treated via the tail vein. The hearts, livers, spleens, lungs, and kidneys of the mice were harvested for a histological analysis to evaluate the biocompatibility of the TBNPs.

In Vitro Antibacterial Evaluation. MRSA and E. coli were used to investigate the antibacterial effects of the TBNPs for six groups (PBS, PBS + light, TB, TB + light, TBNPs, and TBNPs + light $(50 \mathrm{mg} / \mathrm{kg}))$. Bacterial suspensions at a concentration of $1.5 \times 106 \mathrm{CFU} / \mathrm{mL}$ were added to a 96-well plate and then treated under the above conditions for $2 \mathrm{~h}$ at $37^{\circ} \mathrm{C}$. Groups treated with the $660 \mathrm{~nm}$ laser were separately irradiated with a $660 \mathrm{~nm}$ laser for $5 \mathrm{~min}\left(1 \mathrm{~W} / \mathrm{cm}^{2}\right)$. The mixed solution of each treatment group was coated on a solid agar plate and cultured at $37^{\circ} \mathrm{C}$ for $24 \mathrm{~h}$. Morphological changes in bacteria (MRSA and E. coli) treated with TBNPs were observed by SEM.

Detection of Single Oxygen. TB and TBNPs were dispersed in a water solution for single-oxygen tests. The trapping agent used in this test was ABDA, which was pipetted into the solution and mixed homogeneously for preparation. Capillaries were then introduced to load the samples. The capillaries were then placed into an electron paramagnetic resonance (EPR) system (JEOL, JES-FA200, Tokyo, Japan) to collect information on the radicals. Electron spin resonance (ESR) spectra were recorded using a Bruker E500 spectrometer (Karlsruhe, Germany). A mixture of the TBNPs and singlet oxygen $\left({ }^{1} \mathrm{O}_{2}\right)$ trapper (TEMP) in an aqueous solution was transferred to a standard quartz capillary and irradiated by the $660 \mathrm{~nm}$ laser $\left(1 \mathrm{~W} / \mathrm{cm}^{2}\right)$ for different time intervals $(0,4,8,12$, and $16 \mathrm{~s})$ to monitor ${ }^{1} \mathrm{O}_{2}$.

Animal Anti-Infection Model Assay. Female BALB/c mice were selected to establish a skin infection animal model to evaluate the antibacterial potential of TBNPs. The skin on the back was punctured with a sterile syringe needle, inoculated with $5 \times 107 \mathrm{CFU} / \mathrm{mL}$ MRSA $(100 \mu \mathrm{L})$, and infected for one day. The mice successfully infected with MRSA were randomly divided into six groups (three in the light group and three in the nonlight group), with five mice in each group. PBS, TB, and TBNPs were sprayed into the infected area. For the light group, the treatment was carried out at 5 min after spraying. After $24 \mathrm{~h}, 3$ days, and 7 days, clinical examination, bacterial culturing, and biochemical identification were 
performed. Colonies were enumerated and reported as recovered CFU/mL of washing fluid. The skin tissue from each mouse was fixed in a $10 \%$ buffered formalin phosphate at room temperature followed by paraffin embedding. Histological slide preparation and hematoxylin-eosin (H-E) staining were performed. The collected $\mathrm{H}-\mathrm{E}-\mathrm{stained}$ mouse histology sections were visualized using an optical microscope (Olympus X71, Tokyo, Japan). All identities and analyses of the pathology slides were blinded to the pathologist.

Statistical analysis. The data are presented as mean \pm standard deviation. A statistically significant difference was defined by $p<0.05$.

\section{Results}

\subsection{Preparation and Characterization of TBNPs}

The performances of the TBNPs were evaluated by SEM and FTIR spectroscopy. Compared to TB, the FTIR spectrum of the TBNPs showed new absorption bands at 2300 and $1750 \mathrm{~nm}^{-1}$. The absorption band at $2300 \mathrm{~cm}^{-1}$ was attributed to the $\mathrm{C}=\mathrm{O}$ stretching vibration, while the absorption band at $1750 \mathrm{~cm}^{-1}$ was attributed to the bending vibration of the $\mathrm{C}-\mathrm{C}$ skeleton of the benzene ring of TB (Figure 1A). The average size of the TBNPs measured by dynamic light scattering was $201.7 \mathrm{~nm}$ with a polydispersity index of 0.074 (Figures S1 and S2). The zeta potential of the TBNPs was $-8.14 \mathrm{mV}$ (Figure S3). The morphology of the TBNPs was observed by SEM. The TBNPs had a uniform appearance with size in the range of 100-200 nm (Figure S4). The polylactic acid successfully coated the TB. Ultraviolet-visible absorption spectroscopy revealed that the TBNPs exhibited a wide absorption range (ultraviolet to near-infrared) at different concentrations. As shown in Figure 1B, the maximum absorption peak of the TBNPs is $663.5 \mathrm{~nm}$, which is the characteristic wavelength of TB. As shown in Figure S5, a linear regression equation of $y=0.1975 x-0.00669\left(R^{2}=0.99961\right)$ is obtained considering the TB concentration C $(\mu \mathrm{g} / \mathrm{mL})$ as abscissa and the absorbance of the TB solution at $660 \mathrm{~nm}$ as the ordinate. The TBNP encapsulation rate and drug load of the NPs were $87.03 \%$ and $2.24 \%$, respectively.

A

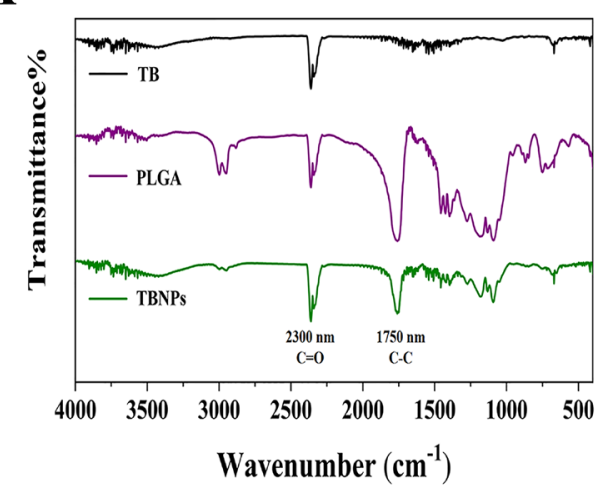

B

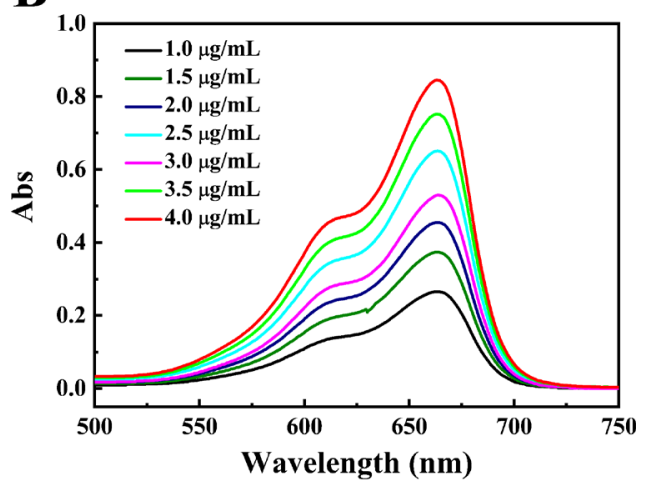

Figure 1. (A) FTIR spectra of TB, PLGA, and TBNPs. (B) Ultraviolet-visible absorption spectra of TBNPs.

\subsection{Hemolysis Test}

A hemolysis test was used to evaluate the interaction between the nanocomposite materials and blood. When the concentration of the TBNP solution reached $400 \mu \mathrm{g} / \mathrm{mL}$, no significant hemolysis occurred (Figure S6), which indicates a good biocompatibility. As shown in Figure S7, the concentration of the TBNP solution reaches $400 \mu \mathrm{g} / \mathrm{mL}$, which corresponds to a rare hemolysis. The red blood cell morphology was normal, without hemolysis (Figure S8). 


\subsection{Phototoxic Cell Assay}

Although TB had a very low toxicity after $5 \mathrm{~min}$ of $660 \mathrm{~nm}$ laser radiation, the physiological behavior of the TBNPs may be significantly different when TB is modified with PLGA. Therefore, the toxicology of the TBNPs requires further evaluation. Different concentrations of TB and TBNPs $(0,3.125,6.25,12.5,25,50,100$, and $200 \mu \mathrm{g} / \mathrm{mL})$ were cultured in $4 \mathrm{~T} 1$ cells after $5 \mathrm{~min}$ of $660 \mathrm{~nm}$ laser irradiation for $24 \mathrm{~h}$. The cell viability was evaluated by an MTT assay. The cell viability of TB at concentrations of 3.125, 6.25, 12.5, 25, 50, 100, and $200 \mu \mathrm{g} / \mathrm{mL}$ was $91.2 \%, 90.4 \%, 89.7 \%, 86.6 \%, 84.2 \%, 86.3 \%$, and $82.6 \%$, respectively (Figure 2A). The cell viability of the TBNPs at concentrations of 3.125, 6.25, 12.5, 25, 50, 100, and $200 \mu \mathrm{g} / \mathrm{mL}$ was $93.2 \%, 91.4 \%, 92.7 \%, 86.6 \%, 84.2 \%, 86.3 \%$, and $84.6 \%$, respectively (Figure 2B). The TB and TBNPs exhibited low phototoxicities in the case without irradiation (Figure S9).

A

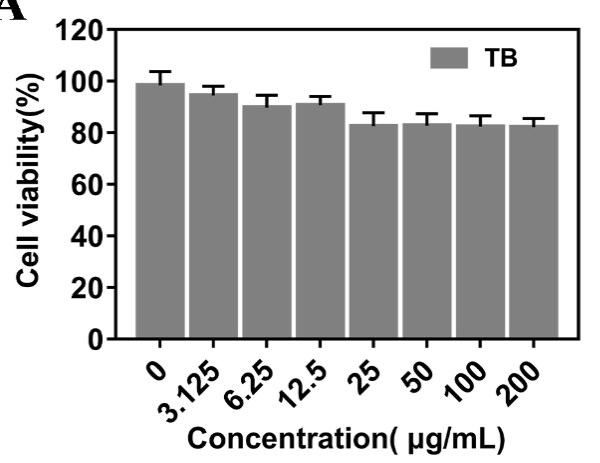

B

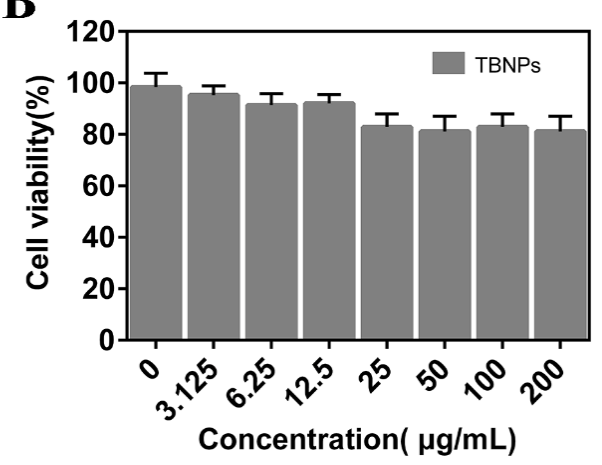

Figure 2. Cell viability experiment. Activities of $4 \mathrm{~T} 1$ cells incubated with (A) TB and (B) TBNPs at different concentrations after $660 \mathrm{~nm}$ laser radiation for $5 \mathrm{~min}$.

The relative activity of $4 \mathrm{~T} 1$ cells did not change significantly after incubation for $24 \mathrm{~h}$ with TB and TBNPs, even at $200 \mu \mathrm{g} / \mathrm{mL}$, which indicates a low cytotoxicity of the tested nanomaterials. This demonstrates that the TBNPs have a low phototoxicity, which can be used in a series of cell experiments and are expected to be used further in animal experiments.

\subsection{In Vivo Toxicity}

Although the biocompatibility of TB has been reported, the toxicity evaluation of TBNPs in vivo has not been carried out. The biological safety of TBNPs was verified in mice. The histopathology with H-E staining indicated no noticeable damage or inflammation in the tissues (the heart, liver, spleen, lungs, and kidneys) from all groups (Figure 3). These results show that the TBNPs had a good biocompatibility in vivo. 


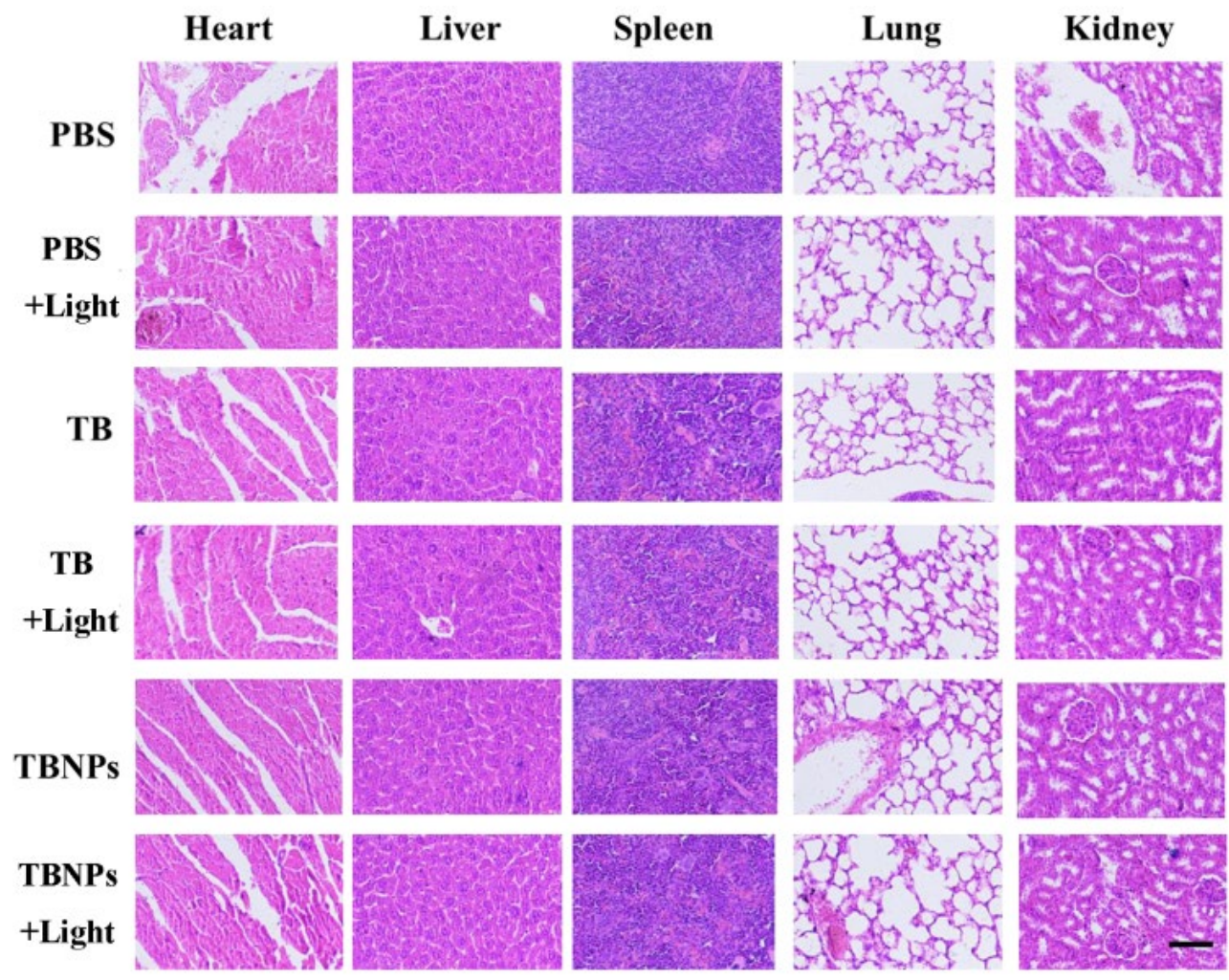

Figure 3. Photomicrographs of H-E-stained slides of the major organs from the mice 14 days after intravenous injection with PBS $(100 \mu \mathrm{L}), \mathrm{TB}(200 \mu \mathrm{g} / \mathrm{mL}, 100 \mu \mathrm{L})$, and TBNPs $(200 \mu \mathrm{g} / \mathrm{mL}, 100 \mu \mathrm{L})$. The scale bar corresponds to $500 \mu \mathrm{m}$.

\subsection{In Vitro Antibacterial Treatment}

The antimicrobial activity of the TBNPs was evaluated using the MIC test. The MIC of the TBNPs for MRSA and E. coli was $100 \mu \mathrm{g} / \mathrm{mL}$ (Figure 4C). However, the MIC of TBNPs + light against $E$. coli (top row) and MRSA (next row) was $25 \mu \mathrm{g} / \mathrm{mL}$ (Figure 4D). The MIC results indicated that the TBNPs + light treatment had an obvious antibacterial effect.

To evaluate the antibacterial activity of the TBNPs by a single laser radiation, MRSA and E. coli were cultured with TBNPs, TB, and PBS before treatment with or without laser irradiation $\left(660 \mathrm{~nm}, 1 \mathrm{~W} / \mathrm{cm}^{2}, 5 \mathrm{~min}\right)$. MRSA or $E$. coli colony counts were measured using the conventional plate count method after $24 \mathrm{~h}$. As shown in Figure 4A,B, the TBNPs + light treatment produces the strongest antibacterial effect, with few colonies surviving in both strains (MRSA and E. coli) on the TBNPs + light-treated plates. In contrast, the colony counts in the PBS and TB treatment groups were relatively high regardless of the irradiation, which indicates that laser irradiation was not a significant factor limiting the bacterial growth. As shown in Figure S5, TB and TBNPs are largely limited, and 27.2\% and $29.7 \%$ of MRSA were killed when the cells were treated with TBNPs and TB $(200 \mu \mathrm{g} / \mathrm{mL})$. However, TB + light exhibited a better antibacterial effect, with few colonies of MRSA surviving on light-treated plates (74.4\%). In contrast, TBNPs + light exhibited an extremely high antibacterial efficiency (99\%). For E. coli, the restrain rate after treatment with TBNPs plus laser was $98.9 \%$, which was significantly higher than those in the other treatment groups (TB: $36.1 \%$, TB + light: 80.6\%, TBNPs: 34.6\%, and PBS + light: $24.9 \%$ ).

Morphological changes in E. coli and MRSA treated with TBNPs and $660 \mathrm{~nm}$ laser were observed by SEM. In the control group, intact cell morphology and smooth surfaces were observed in MRSA (Figure 4E) and E. coli (Figure 4G), respectively. Compared to the control group, in the TBNPs + light group, some E. coli cells were significantly wrinkled (Figure 4H); certain MRSAs adhered to each other, had different sizes, spillage of the contents occurred (Figure 4F); most of the bacteria were killed; and the normal morphology 
of bacteria disappeared. The significant improvement in the antibacterial activity of the TBNPs was attributed to the synergistic PDT/TBNPs. TBNPs bind to bacterial membranes. The PDT can destroy the outer membrane of bacteria by producing ROS, thereby enhancing the antibacterial properties.

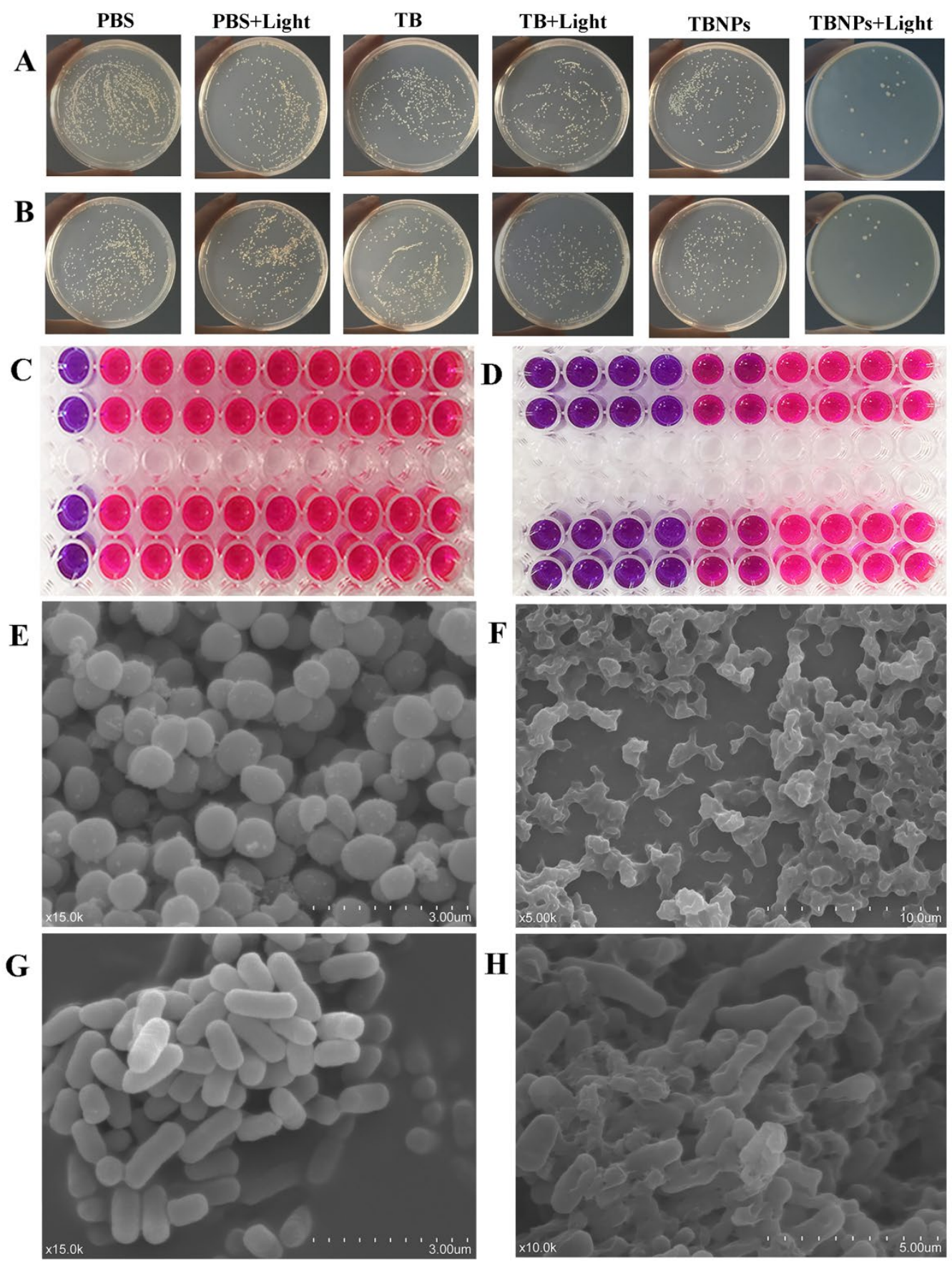

Figure 4. Photographs of bacterial colonies formed on LB agar plates of (A) E. coli and (B) MRSA (PBS, PBS + light, TB, TB + light, TBNPs, and TBNPs + light). (C) Image of the MIC of TB against $E$. coli and MRSA. (D) Image of the MIC of TBNPs with the $660 \mathrm{~nm}$ laser against E. coli and MRSA. SEM images of (E) MRSA in PBS, (F) MRSA treated with TBNPs under the laser, $(\mathbf{G})$ E. coli in PBS, and (H) E. coli treated with TBNPs under the laser. 


\subsection{Treatment of the MRSA-Infected Wound}

An animal model of skin infection induced by MRSA was established to confirm the antibacterial effects of TBNPs under laser irradiation. The infected BALB/c mice were divided into six groups (PBS, PBS + light, TB, TB + light, TBNPs, and TBNPs + light; five mice per group). The BALB/c mice in the laser treatment group were irradiated with the $660 \mathrm{~nm}$ laser at $1 \mathrm{~W} / \mathrm{cm}^{2}$ for $5 \mathrm{~min}$. The appearance of the skin of each mouse was recorded every three days. In the gross examination, after the treatment for 1 day, swelling and red exudates were observed in the wound skin in the PBS, PBS + light, TB, and TB + light groups. In contrast, no obvious swelling or exudates were observed in the wounded skin in the TBNPs + light group. After treatment for 4 days, the wounds of the other groups were black or red, while the wounds of the TBNPs + light group were pale red. The areas of wounded skin were significantly smaller in the TBNPs + light group than in the others. On the seventh day after infection, the wound of the TBNPs + light group was well healed, with no significant crusting or ulceration, while the other groups formed scabs with different sizes (Figure 5A). In the histological examination, the TBNPs + light group did not exhibit obvious skin abnormalities, while the other groups of mice exhibited an incomplete epidermal morphology, severe edema tissue, and a large amount of leukocyte infiltration in the wound and surrounding tissue (Figure 5C and Figure S10). This suggests that the TBNPs + light group therapy had a significant promoting effect on wound healing. Similarly, the body weights of each group of mice were recorded. The body weights of the animals in each group increased steadily (Figure S11).

A

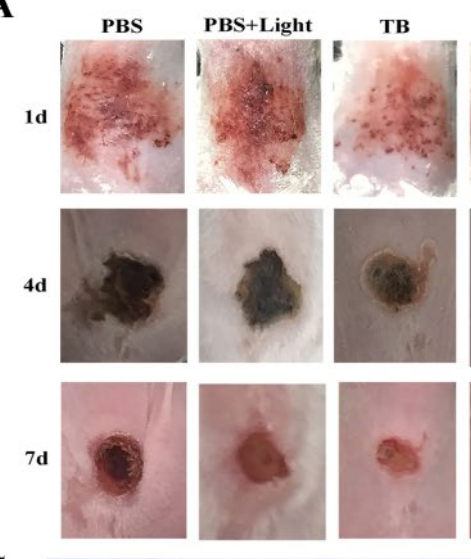

C

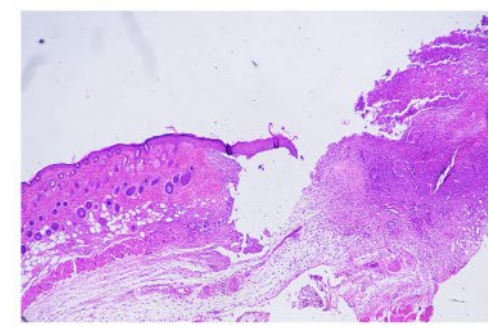

PBS
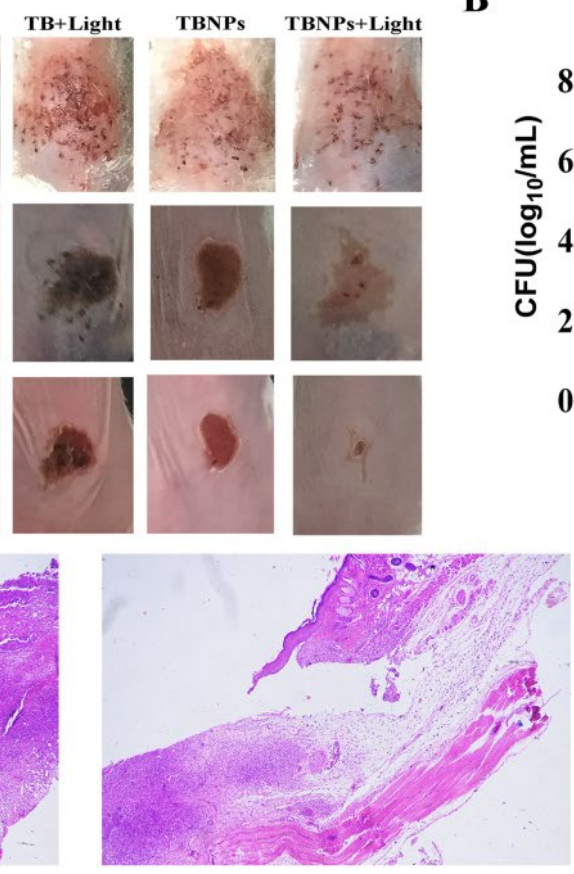

TB+Light
B
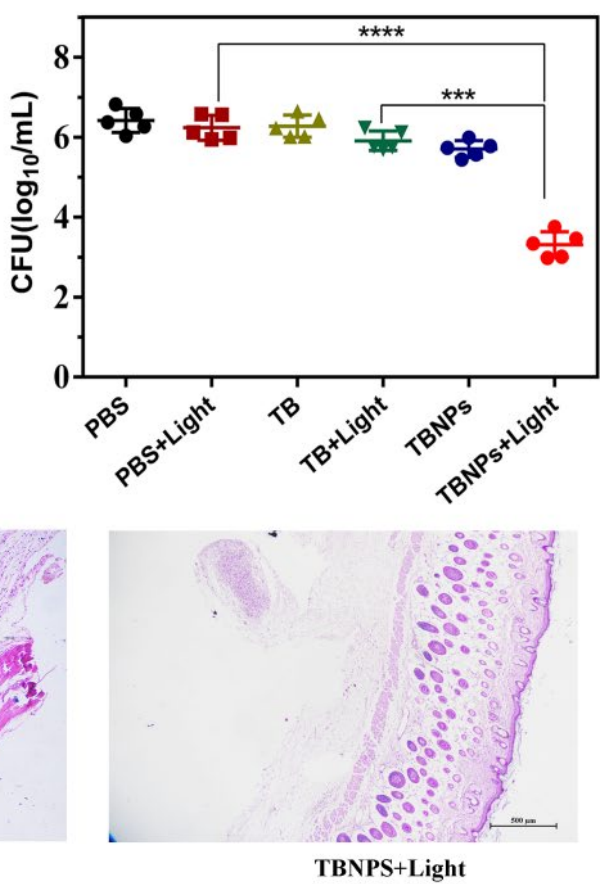

Figure 5. (A) Photographs of infected wounds in mice at different time points after various treatments. (B) Numbers of viable MRSAs in infected wounds after different treatments determined by the plate counting method. (C) Photomicrographs of tissue sections of MRSA-infected wounds in mice treated with PBS, TB + light, and TBNPs + light after H-E staining. The scale bar corresponds to $500 \mu \mathrm{m} .{ }^{* * * *}$ very significant difference, ${ }^{* * *}$ significant difference.

Further, in the process of wound healing, the size of the infected wound was measured every 3 days. As shown in Figure S12, the infected wound areas of PBS, PBS + light, TB, TB + light, TBNPs, and TBNPs + light were significantly different. On day 1, the size of the wound skin in these groups was not significantly different. On days 3 and 7 , the size of skin wounds in the TBNPs group was significantly smaller than those in the other groups. 
PLGA promotes angiogenesis and accelerates the wound healing. Therefore, $\mathrm{TB}+$ light promotes wound healing during the sterilization process.

MRSA colony counting was performed at the wound sites 1, 4, and 7 days post treatment (Figure S13). The MRSA value in the PBS group was similar to that in the PBS + light group, while those in the TB and TB + light groups were decreased by only $0.14 \log$ and $0.50 \mathrm{log}$, respectively (Figure 5B). The restraining effect of TBNPs on MRSA under laser irradiation can reach approximately 3 logs, which indicates that the photothermal enhancement therapy of TBNPs has a significant bactericidal effect on wounds infected by MRSA compared to that of the other groups. Consistent with the wound healing results, the bacteria in the TBNPs + light group were significantly reduced. Therefore, the laser irradiation of TBNPs can significantly inhibit the bacterial growth and promote wound healing.

\subsection{Antibacterial Mechanism of TBNPs}

In vitro and in vivo experiments confirmed that TBNPs have excellent antibacterial effects under laser irradiation. We suspected that TBNPs had a good antibacterial effect under laser irradiation because TBNPs produced more ${ }^{1} \mathrm{O}_{2}$. TB was used as a reference agent, while ABDA was used as a ${ }^{1} \mathrm{O}_{2}$ scavenger to test the ${ }^{1} \mathrm{O}_{2}$ produced by TBNPs under laser irradiation. The significant decrease in $\mathrm{ABDA}$ absorption demonstrated the good ${ }^{1} \mathrm{O}_{2}$ generation ability of TBNPs in water (Figure 6A). As shown in Figure 6B, the decomposition rate of ABDA in the presence of TBNPs is considerably higher than that of TB. EPR and ESR analyses also showed a better capacity for the generation of ${ }^{1} \mathrm{O}_{2}$ by TBNPs compared to TB under $660 \mathrm{~nm}$ laser irradiation (Figure 6C,D).

A

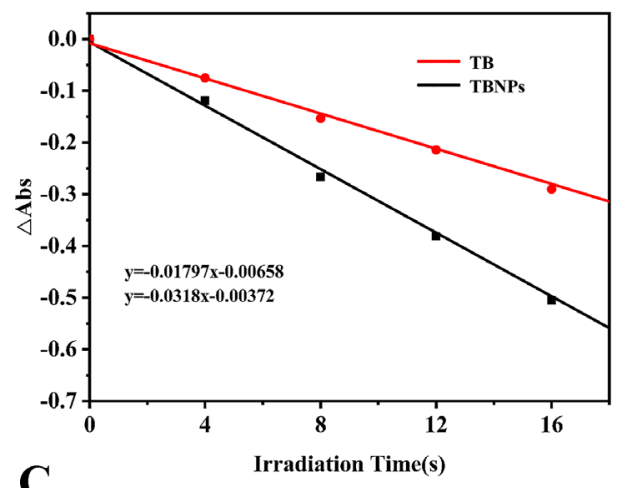

C

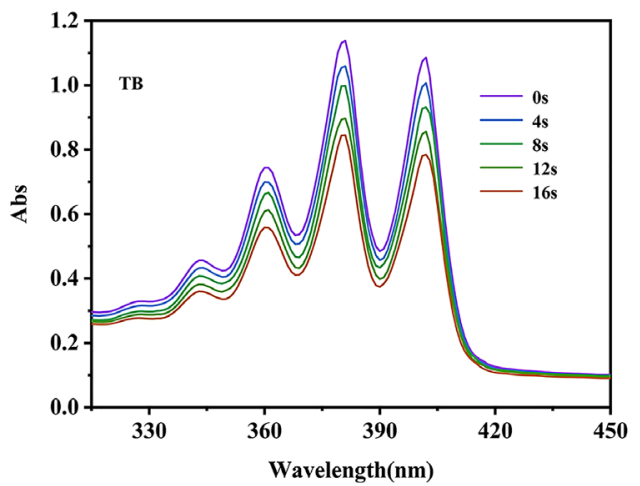

B
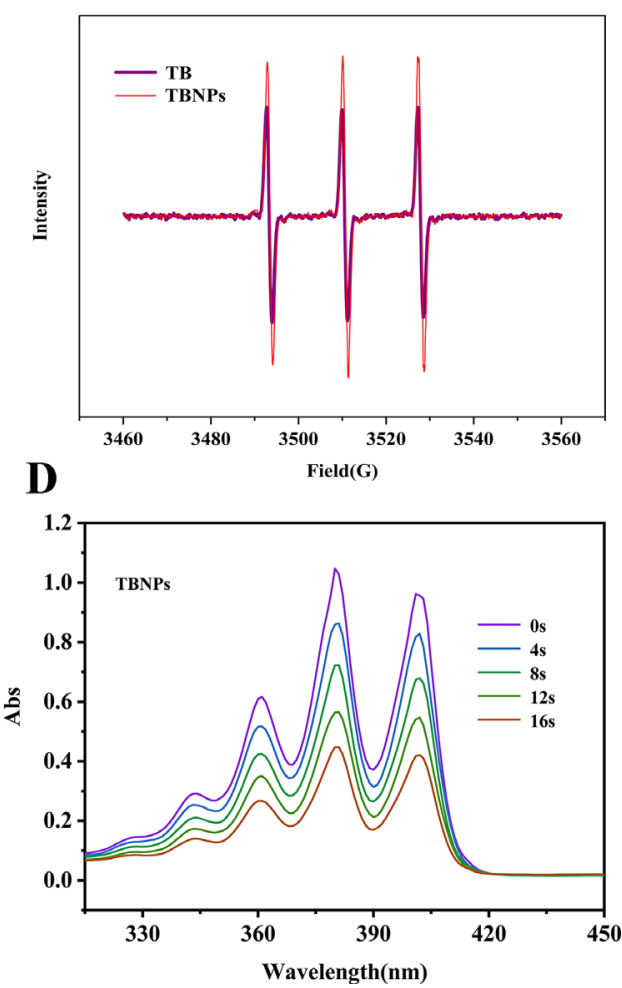

Figure 6. (A) Decay plots of ABDA absorption in the presence of TB and TBNPs in water. (B) EPR spectra of TB and TBNPs. Absorption spectra of ABDA mixed with (C) TB and (D) TBNPs in an aqueous solution with $660 \mathrm{~nm}$ laser irradiation.

In this study, the hypothetical antibacterial mechanism of TBNPs + light therapy is that ${ }^{1} \mathrm{O}_{2}$ produced by TBNPs is more than that of TB under $660 \mathrm{~nm}$ irradiation, which is due to the reduced stack-up effect of ${ }^{1} \mathrm{O}_{2}$ produced by TBNPs. 


\section{Discussion}

Bacterial infections are the most common complication of wounds and account for one-third of global mortality [28]. However, the excessive use of antibiotics has led to the emergence of drug-resistant bacteria, posing a serious threat to public health [29]. Thus, the development of effective treatment modalities is of paramount significance.

PDT is considered a promising antibacterial method. Numerous studies have been carried out on PDT using visible light and different photosensitizers [30-32]. To obtain a better bactericidal effect, photosensitizers with a high affinity for bacterial cells have been investigated. TB, as a traditional photosensitizer, is limited in clinical applications due to the ACQ effect [33]. The antibacterial effect of PDT is generally attributed to the formation of ROS that do not induce drug resistance [34]. The purpose of this study was to investigate the antibacterial effect of TB and TBNPs and provide an effective method to solve global health problems.

In this study, TBNPs were successfully prepared using an ultrasound-assisted coating method and characterized. In the ultraviolet-visible spectrum, the TBNPs exhibited a characteristic peak at $660 \mathrm{~nm}$, which is consistent with previous reports [35,36]. According to the FTIR results, TB was successfully encapsulated into the PLGA NPs. The encapsulation rate of TBNPs was $87.03 \%$, which was higher than those of other nanomaterials reported in the literature [37]. The antibacterial experiment of TBNPs confirmed that TBNPs have excellent antibacterial effects, which may be related to the high $\mathrm{TB}$ encapsulation rate and PDT. ROS generation is the key to PDT. More ${ }^{1} \mathrm{O}_{2}$ was detected in TB-irradiated cells than in unirradiated cells. The main target of ROS is the cell membrane, which can lead to protein leakage and lipid peroxidation, causing bacterial DNA breakage and, ultimately, bacterial death [38,39]. The ACQ effect is one of the factors affecting the application of nanomaterials [40]. In recent years, many hydrophobic counterions have been proposed as effective structures to reduce the ACQ. However, the role of the counterion structure is still poorly understood [41]. As a hydrophobic counterion material, PLGA increases the encapsulation efficiency of dyes [42]. Numerous PDT nanomaterials are used in antibacterial applications owing to their unique antibacterial effects. Porphyrin-mediated PDT may kill bacteria by destroying the cell wall and membrane of bacteria [43], while ICG-PDT can thin the cell wall of MRSA and drive the transformation of MRSA to the sensitive phenotype of oxacillin, which can achieve excellent results in coordination with antibiotic use [44]. In addition, PDT nanomaterials have a significant role not only in the antibacterial activity, but also in the antifungal and antiparasitic activities. Phenothiazines, phthalocyanines, porphyrin, and porphyrinic precursor aminolevulinic acid plus PDT fungi have a positive role in the treatment [45]. PLGA prepared in this study coated the TB, increased the encapsulation rate of TB, largely reduced the ACQ effect, and improved the antibacterial effect of TBNPs. In addition, PLGA can promote the function of TBNPs in the anti-infection repair of injured skin because of its ability to promote angiogenesis and wound healing.

This study confirmed that PLGA-coated TBNPs had significant antibacterial effects against MRSA and E. coli. TBNPs have higher binding efficiency and ROS production than free $\mathrm{TB}$, which suggests that it enhances the PDT. The enhanced activity is attributed to the relatively high loading capacity and the TBNPs attenuating the ACQ effect of TB, which reveals the advantage of TBNPs in PDT.

\section{Conclusions}

In this study, a PLGA-coated TB antibacterial nanomaterial was successfully synthesized, which has a photodynamic effect and produces more ROS, with a high antibacterial ability. TBNPs are broad-spectrum antibacterial materials with a good antibacterial activity against MRSA and E. coli with synergistic PDT. TBNPs can reduce the ACQ effect of TB, thus increasing the PDT effect of TB. In addition, TBNPs can produce more ROS in coordination with PDT to achieve better antibacterial effects. In vivo animal studies further demonstrated that the TBNPs could promote wound healing by reducing inflammation and 
increasing the collagen deposition and blood vessel formation. The TBNPs obtained in this study are biocompatible and hemocompatible, having a broad spectrum of antibacterial activity, and can be used as a safe and curable alternative for the treatment of chronic, persistent skin injuries and drug-resistant bacterial infections.

Supplementary Materials: The following are available online at https://www.mdpi.com/article/10 .3390 / nano11123394/s1, Figure S1 Hydration diameter distribution of TBNPs in water. Figure S2 The DLS analysis of TBNPs in water. Figure S3 Zeta of TBNPs in pure water. Figure S4 TBNPs SEM images. Figure S5 Restrain rate of different groups against E. coli and MRSA. Figure S6 Hemolysis of red blood cells (RBCs) treated with control, TBNPs $\left(10,50,100\right.$, and $\left.400 \mu \mathrm{g} \mathrm{mL}^{-1}\right)$ and Triton-X100 solution. Figure S7 Hemolysis percentage of red blood cells (RBCs) treated with TBNPs solution. Figure S8 The photograph under a microscope of red blood cells (RBCs). Figure S9 Weight curve of mice within 7 days after mice was injected different groups (PBS, PBS + light, TB, TB + light, TBNPs and TBNPs + light). Figure S10 Activities of 4T1 cells incubated with TB and TBNPs at different concentrations. Figure S11 Photomicrographs of tissue sections of MRSA-infected wounds in mice treated with TB and TBNPs after H\&E staining. The scale bar is $500 \mu \mathrm{m}$. Figure $\mathrm{S} 12$ The relative wound area in different groups (PBS group, PBS + light group, TB group, TB + light group, TBNPs group and TBNPs + light group). Figure S13 Photographs of bacterial colonies formation on LB agar plates from the infected wounds after $7 \mathrm{~d}$ treatments.

Author Contributions: T.L. designed the study. B.L. and X.X. wrote this article. X.X., B.L., H.W., Y.Z., X.T. and J.T. performed the laboratory experiments. All authors have read and agreed to the published version of the manuscript.

Funding: This research was funded by the Young Teachers Innovation Project of China Agricultural University (2018QC142), National Natural Science Foundation of China (Project No. 31802162), and Beijing Natural Science Foundation (6202017).

Institutional Review Board Statement: Animal experiments were approved by the Animal Ethics Committee of China Agricultural University (approval date: 20180307) and were performed in accordance to Regulations of Experimental Animals of Beijing Authority.

Informed Consent Statement: Not applicable.

Data Availability Statement: The data presented in this study are available on request from the corresponding author.

Conflicts of Interest: The authors declare no conflict of interest.

\section{References}

1. Willenborg, S.; Eming, S.A. Cellular networks in wound healing. Science 2018, 362, 891-892. [CrossRef]

2. Qu, J.; Zhao, X.; Liang, Y.; Xu, Y.; Ma, P.X.; Guo, B. Degradable conductive injectable hydrogels as novel antibacterial, anti-oxidant wound dressings for wound healing. Chem. Eng. J. 2019, 362, 548-560. [CrossRef]

3. Heher, P.; Mühleder, S.; Mittermayr, R.; Redl, H.; Slezak, P. Fibrin-based delivery strategies for acute and chronic wound healing. Adv. Drug Deliv. Rev. 2018, 129, 134-147. [CrossRef] [PubMed]

4. Wang, Z.; Hu, W.; Du, Y.; Xiao, Y.; Mao, C. Green Gas-Mediated Cross-Linking Generates Biomolecular Hydrogels with Enhanced Strength and Excellent Hemostasis for Wound Healing. ACS Appl. Mater. Interfaces 2020, 12, 13622-13633. [CrossRef] [PubMed]

5. Kharkwal, G.B.; Sharma, S.K.; Huang, Y.Y.; Dai, T.; Hamblin, M.R. Photodynamic Therapy for Infections: Clinical Applications. Lasers Surg. Med. 2011, 43, 755-767. [CrossRef]

6. Kardas, P.; Devine, S.; Golembesky, A.; Roberts, C. A systematic review and meta-analysis of misuse of antibiotic therapies in the community. Int. J. Antimicrob. Agents 2005, 26, 106-113. [CrossRef]

7. Lindholm, C.; Searle, R. Wound management for the 21st century: Combining effectiveness and efficiency. Int. Wound J. 2016, 13, 5-15. [CrossRef] [PubMed]

8. Hamblin, M.R.; O’Donnell, D.; Murthy, N.; Contag, C.H.; Hasan, T. Rapid control of wound infections by targeted photodynamic therapy monitored by in vivo bioluminescence imaging. Photochem. Photobiol. 2010, 75, 51-57. [CrossRef]

9. Paolillo, F.R.; Rodrigues, P.; Bagnato, V.S.; Alves, F.; Corazza, A.V. The effect of combined curcumin-mediated photodynamic therapy and artificial skin on Staphylococcus aureus-infected wounds in rats. Lasers Med. Sci. 2020, 36, 1219-1226. [CrossRef] [PubMed]

10. Gong, N.; Tan, Y.; Li, M.; Lu, W.; Lei, X. ALA-PDT combined with antibiotics for the treatment of multiple skin abscesses caused by Mycobacterium fortuitum. Photodiagnosis Photodyn. Ther. 2016, 15, 70-72. [CrossRef] 
11. Su, G.; Wei, Z.; Wang, L.; Shen, J.; Liang, Q. Evaluation of Toluidine Blue-Mediated Photodynamic Therapy for Experimental Bacterial Keratitis in Rabbits. Transl. Vis. Sci. Technol. 2020, 9, 13. [CrossRef] [PubMed]

12. Sun, L.; Jiang, W.; Zhang, H.; Guo, Y.; Chen, W.; Jin, Y.; Chen, H.; Du, K.; Dai, H.; Ji, J.; et al. Photosensitizer-Loaded Multifunctional Chitosan Nanoparticles for Simultaneous in Situ Imaging, Highly Efficient Bacterial Biofilm Eradication, and Tumor Ablation. ACS Appl. Mater. Interfaces 2018, 11, 2302-2316. [CrossRef]

13. Li, J.; Zhu, M.; An, L.; Chen, F.; Zhang, X. Fungicidal efficacy of photodynamic therapy using methylene blue against Sporothrix globosa in vivo and in vivo. Eur. J. Dermatol. 2019, 29, 160-166. [CrossRef]

14. Jerjes, W.; Hamdoon, Z.; Hopper, C. Photodynamic therapy in the management of basal cell carcinoma: Retrospective evaluation of outcome. Photodiagnosis Photodyn. Ther. 2017, 19, 22-27. [CrossRef]

15. Ding, C.; Ma, Y.Y.; Wang, P.; Liu, J. Multiple Bowen's diseases and basal cell carcinomas in a patient with acute promyelocytic leukemia treated with arsenic trioxide: A case report and effective treatment with photodynamic therapy. Dermatol. Ther. 2018, 31, 6. [CrossRef] [PubMed]

16. Itoh, Y. Photodynamic therapy of acne vulgaris with topical delta-aminolaevulinic acid and incoherent light in Japanese patients. Br. J. Dermatol. 2015, 144, 575-579. [CrossRef]

17. Topaloglu, N.; Gueney, M.; Yuksel, S.; Guelsoy, M. Antibacterial photodynamic therapy with 808-nm laser and indocyanine green on abrasion wound models. J. Biomed. Opt. 2015, 20, 28003. [CrossRef]

18. Abrahamse, H.; Hamblin, M.R. New photosensitizers for photodynamic therapy. Biochem. J. 2016, 473, 347-364. [CrossRef] [PubMed]

19. Wardlaw, J.L.; Sullivan, T.J.; Lux, C.N.; Austin, F.W. Photodynamic therapy against common bacteria causing wound and skin infections. Vet. J. 2012, 192, 374-377. [CrossRef]

20. Xu, X.; Hu, Y.; Zhang, L.P.; Liu, B.; Liu, T. Lactic-: Co -glycolic acid-coated methylene blue nanoparticles with enhanced antibacterial activity for efficient wound healing. RSC Adv. 2020, 10, 12304-12307. [CrossRef]

21. Zheng, Y.; Yu, E.; Weng, Q.; Zhou, L.; Li, Q. Optimization of hydrogel containing toluidine blue O for photodynamic therapy in treating acne. Lasers Med. Sci. 2019, 34, 1535-1545. [CrossRef]

22. Liao, H.T.; Lai, Y.T.; Kuo, C.Y.; Chen, J.P. A bioactive multi-functional heparin-grafted aligned poly(lactide-co-glycolide)/curcumin nanofiber membrane to accelerate diabetic wound healing. Mater. Sci. Eng. C 2020, 120, 111689. [CrossRef]

23. Mir, M.; Ahmed, N.; Rehman, A.U. Recent applications of PLGA based nanostructures in drug delivery. Colloids Surf. B Biointerfaces 2017, 159, 217-231. [CrossRef]

24. Daristotle, J.L.; Lau, L.W.; Erdi, M.; Hunter, J.; Djoum, A., Jr.; Srinivasan, P.; Wu, X.; Basu, M.; Ayyub, O.B.; Sandler, A.D.; et al. Sprayable and biodegradable, intrinsically adhesive wound dressing with antimicrobial properties. Bioeng. Transl. Med. 2020, 5, 10149. [CrossRef]

25. Jochen, R.; Ann-Kristin, U.; Ingrid, M.; Tobias, W.; Jürgen, G.; Christian, S.; Hans-Peter, W.; Stefanie, K. Preventing Surgical Site Infections Using a Natural, Biodegradable, Antibacterial Coating on Surgical Sutures. Molecules 2017, 22, 1570. [CrossRef]

26. Porporato, P.E.; Payen, V.L.; Saedeleer, C.; Préat, V.; Thissen, J.P.; Feron, O.; Sonveaux, P. Lactate stimulates angiogenesis and accelerates the healing of superficial and ischemic wounds in mice. Angiogenesis 2012, 15, 581-592. [CrossRef] [PubMed]

27. Park, H.; Lee, K.Y.; Lee, S.J.; Park, K.E.; Park, W.H. Plasma-treated poly(lactic- co -glycolic acid) nanofibers for tissue engineering. Macromol. Res. 2007, 15, 238-243. [CrossRef]

28. Nathwani, D. Treatment of infections caused by multidrug-resistant Gram-negative bacteria: Report of the British Society for Antimicrobial Chemotherapy/Healthcare Infection Society/British Infection Association Joint Working Party Foreword. J. Antimicrob. Chemother. 2018, 73, III1. [CrossRef]

29. Morris, D.O.; Loeffler, A.; Davis, M.F.; Guardabassi, L.; Weese, J.S. Recommendations for approaches to meticillin-resistant staphylococcal infections of small animals: Diagnosis, therapeutic considerations and preventative measures. Vet. Dermatol. 2017, 28, 304. [CrossRef]

30. Hashimoto, M.; Prates, R.A.; Kato, I.T.; Núez, S.C.; Ribeiro, M.S. Antimicrobial Photodynamic Therapy on Drug-resistant Pseudomonas aeruginosa-induced Infection. An In Vivo Study. Photochem. Photobiol. 2012, 88, 590-595. [CrossRef]

31. Park, J.H.; Ahn, M.Y.; Kim, Y.C.; Kim, S.A.; Moon, Y.H.; Ahn, S.G.; Yoon, J.H. In Vitro and in Vivo Antimicrobial Effect of Photodynamic Therapy Using a Highly Pure Chlorin e6 against Staphylococcus aureus Xen29. Biol. Pharm. Bull. 2012, 35, 509. [CrossRef]

32. Simonetti, O.; Cirioni, O.; Orlando, F.; Alongi, C.; Lucarini, G.; Silvestri, C.; Zizzi, A.; Fantetti, L.; Roncucci, G.; Giacometti, A. Effectiveness of antimicrobial photodynamic therapy with a single treatment of RLP068/Cl in an experimental model of Staphylococcus aureus wound infection. Br. J. Dermatol. 2011, 164, 987-995. [CrossRef] [PubMed]

33. Eng, B. Porphysome Nanovesicles Generated By Porphyrin Bilayers for use as Multimodal Biophotonic Contrast Agents. Nano Biomed. Eng. 2011, 10, 324-332. [CrossRef]

34. Sehmi, S.K.; Noimark, S.D.; Pike, S.; Bear, J.C.; Peveler, W.J.; Williams, C.K.; Shaffer, M.; Allan, E.; Parkin, I.P.; MacRobert, A.J. Enhancing the Antibacterial Activity of Light-Activated Surfaces Containing Crystal Violet and ZnO Nanoparticles: Investigation of Nanoparticle Size, Capping Ligand, and Dopants. ACS Omega 2016, 1, 334-343. [CrossRef] [PubMed]

35. Robinson-Duggon, J.; Pizarro, N.; Gunther, G.; Zúñiga-Núñez, D.; Fuentealba, D. Fatty Acid Conjugates of Toluidine Blue O as Amphiphilic Photosensitizers: Synthesis, Solubility, Photophysics and Photochemical Properties. Photochem. Photobiol. 2020, 97, 71-79. [CrossRef] 
36. ElZorkany, E.S.; Youssef, T.; Mohamed, M.B.; Amin, R.M. Photothermal versus photodynamic treatment for the inactivation of the bacteria Escherichia coli and Bacillus cereus: An in vitro study. Photodiagnosis Photodyn. Ther. 2019, 27, 317-326. [CrossRef] [PubMed]

37. Parasuraman, P.; Antony, A.P.; Sruthil, L.S.B.; Sharan, A.; Syed, A. Antimicrobial photodynamic activity of toluidine blue encapsulated in mesoporous silica nanoparticles against Pseudomonas aeruginosa and Staphylococcus aureus. Biofouling 2019, 35, 89-103. [CrossRef]

38. Misba, L.; Kulshrestha, S.; Khan, A.U. Antibiofilm action of a toluidine blue O-silver nanoparticle conjugate on Streptococcus mutans: A mechanism of type I photodynamic therapy. Biofouling 2016, 32, 313-328. [CrossRef]

39. Misba, L.; Zaidi, S.; Khan, A.U. A comparison of antibacterial and antibiofilm efficacy of phenothiazinium dyes between Gram positive and Gram negative bacterial biofilm. Photodiagnosis Photodyn. Ther. 2017, 18, 24-33. [CrossRef]

40. Klymchenko, A.S.; Roger, E.; Anton, N.; Anton, H.; Shulov, I.; Vermot, J.; Mely, Y.; Vandamme, T.F. Highly lipophilic fluorescent dyes in nano-emulsions: Towards bright non-leaking nano-droplets. RSC Adv. 2012, 2, 11876-11886. [CrossRef]

41. Reisch, A.; Runser, A.; Arntz, Y.; Mély, Y.; Klymchenko, A.S. Charge-Controlled Nanoprecipitation as a Modular Approach to Ultrasmall Polymer Nanocarriers: Making Bright and Stable Nanoparticles. ACS Nano 2015, 9, 5104-5116. [CrossRef]

42. Andreiuk, B.; Reisch, A.; Bernhardt, E.; Klymchenko, A.S. Fighting Aggregation-Caused Quenching and Leakage of Dyes in Fluorescent Polymer Nanoparticles: Universal Role of Counterion. Chem. Asian J. 2019, 14, 836-846. [CrossRef]

43. Iluz, N.; Maor, Y.; Keller, N.; Malik, Z. The synergistic effect of PDT and oxacillin on clinical isolates of Staphylococcus aureus Lasers Surg. Med. 2018, 50, 535-551. [CrossRef] [PubMed]

44. Wong, T.W.; Liao, S.Z.; Ko, W.C.; Wu, C.J.; Wu, S.B.; Chuang, Y.C.; Huang, I.H. Indocyanine Green-Mediated Photodynamic Therapy Reduces Methicillin-Resistant Staphylococcus aureus Drug Resistance. J. Clin. Med. 2019, 8, 411. [CrossRef] [PubMed]

45. Calzavara-Pinton, P.G.; Venturini, M.; Capezzera, R.; Sala, R.; Zane, C. Photodynamic therapy of interdigital mycoses of the feet with topical application of 5-aminolevulinic acid. Photodermatol. Photoimmunol. Photomed. 2004, 20, 144-147. [CrossRef] [PubMed] 